Atmos. Chem. Phys., 17, 12827-12843, 2017

https://doi.org/10.5194/acp-17-12827-2017

(C) Author(s) 2017. This work is distributed under

the Creative Commons Attribution 3.0 License.
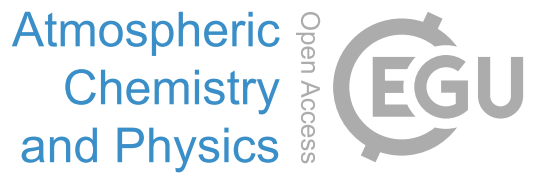

\title{
Adverse effects of increasing drought on air quality via natural processes
}

\author{
Yuxuan Wang ${ }^{1,2, *}$, Yuanyu Xie ${ }^{1, *}$, Wenhao Dong ${ }^{1}$, Yi Ming ${ }^{3}$, Jun Wang ${ }^{4}$, and Lu Shen \\ ${ }^{1}$ Department of Earth System Sciences, Tsinghua University, Beijing, China \\ ${ }^{2}$ Department of Earth and Atmospheric Sciences, University of Houston, Houston, TX, USA \\ ${ }^{3}$ NOAA/Geophysical Fluid Dynamics Laboratory, Princeton, NJ, USA \\ ${ }^{4}$ Center for Global and Regional Environmental Research \& Dept. of Chemical and Biochemical Engineering \\ \& Interdisciplinary Graduate Program in GeoInformatics, University of Iowa, Iowa City, IA, USA \\ ${ }^{5}$ School of Engineering and Applied Science, Harvard University, Cambridge, MA, USA \\ *These authors contributed equally to this work.
}

Correspondence to: Yuxuan Wang (ywang246@central.uh.edu) and Yuanyu Xie (xieyy12@mails.tsinghua.edu.cn)

Received: 13 March 2017 - Discussion started: 28 April 2017

Revised: 5 August 2017 - Accepted: 25 September 2017 - Published: 27 October 2017

\begin{abstract}
Drought is a recurring extreme of the climate system with well-documented impacts on agriculture and water resources. The strong perturbation of drought to the land biosphere and atmospheric water cycle will affect atmospheric composition, the nature and extent of which are not well understood. Here we present observational evidence that US air quality is significantly correlated with drought severity. Severe droughts during the period of 1990-2014 were found associated with growth-season (March-October) mean enhancements in surface ozone and $\mathrm{PM}_{2.5}$ of $3.5 \mathrm{ppbv}(8 \%)$ and $1.6 \mu \mathrm{g} \mathrm{m}^{-3}(17 \%)$, respectively. The pollutant enhancements associated with droughts do not appear to be affected by the decreasing trend of US anthropogenic emissions, indicating natural processes as the primary cause. Elevated ozone and $\mathrm{PM}_{2.5}$ are attributed to the combined effects of drought on deposition, natural emissions (wildfires, biogenic volatile organic compounds (BVOCs), and dust), and chemistry. Most climate-chemistry models are not able to reproduce the observed correlations of ozone and $\mathrm{PM}_{2.5}$ to drought severity. The model deficiencies are partly attributed to the lack of drought-induced changes in land-atmosphere exchanges of reactive gases and particles and misrepresentation of cloud changes under drought conditions. By applying the observed relationships between drought and air pollutants to climate model projected drought occurrences, we estimate an increase of 1-6\% for ground-level $\mathrm{O}_{3}$ and 1$16 \%$ for $\mathrm{PM}_{2.5}$ in the US by 2100 compared to the $2000 \mathrm{~s}$
\end{abstract}

due to increasing drought alone. Drought thus poses an important aspect of climate change penalty on air quality, and a better prediction of such effects would require improvements in model processes.

\section{Introduction}

Air pollution is a major global health risk (Forouzanfar et al., 2015). Chronic and acute exposure to enhanced ozone $\left(\mathrm{O}_{3}\right)$ and fine particulate matter with diameters less than $2.5 \mu \mathrm{m}$ $\left(\mathrm{PM}_{2.5}\right)$ has been associated with many adverse health impacts and premature mortality (Lelieveld et al., 2015). Ambient $\mathrm{O}_{3}$ and $\mathrm{PM}_{2.5}$ concentrations are strongly regulated not only by the atmosphere but also by land-atmosphere interactions through emission and deposition processes. To date, the variation of air quality with climate change has not been fully revealed as most analysis in the past were conducted with respect to atmospheric parameters or events only, such as temperature (Steiner et al., 2010), precipitation (Dawson et al., 2007; Allen et al., 2015), and short-term (in the order of days) meteorological anomalies (e.g., heat/cold waves, air stagnation, and temperature inversion) (Filleul et al., 2006; Qu et al., 2015; Hou and Wu, 2016). The impact of changing hydroclimate on air pollution is largely unexplored and highly uncertain, particularly with respect to droughts, a type of complex extremes on the timescale of weeks to months or 
longer which affect not only the atmosphere but also its interactions with the land biosphere.

Drought is characterized by a prolonged period of precipitation shortage and soil moisture deficit in combination with high temperatures (Trenberth et al., 2014). Drought impacts on agriculture and water resources have been extensively documented (Rosenzweig et al., 2001; Arnell, 2004). With regard to air pollution, drought can reduce wet scavenging of pollutants, affect their chemical production/loss, and change their atmospheric lifetime. Drought also influences the health and conditions of soil and vegetation cover across the landscape, thus perturbing upward transmission of dusts (Prospero and Lamb, 2003) and reactive gases (e.g., biogenic volatile organic compounds, or BVOCs, and $\mathrm{NO}_{x}$ ) (Fuentes et al., 2000; Guenther et al., 2012; Guenther, 2015; Davidson et al., 2008) from the surface into the atmosphere as well as downward dry deposition of gases and aerosols (Huang et al., 2016). Complications such as increasing wildfires and changing human activities (Westerling et al., 2003; Scanlon et al., 2013) further compound the effects of drought on atmospheric composition. Previous studies illustrated one or two aspects of the complex effects of drought on atmospheric composition. For example, Westerling and Swetnam (2003) and Prospero and Lamb (2003) explored the potential risks of increasing wildfire and dust emissions under drought conditions. Tian et al. (2016) analyzed the combined effects of increasing drought and increasing ozone levels on crop production in China, although in their study the ozone change was not linked to drought change. Our prior analysis (Wang et al., 2015) showed a $26 \%$ enhancement of surface $\mathrm{PM}_{2.5}$ concentrations in the southern US during the severe summer drought conditions in 2011, and suggested wildfires and cloud processes as key factors responsible for the change of $\mathrm{PM}_{2.5}$ during drought. A comprehensive assessment of air pollution changes during different drought periods has yet to be conducted to verify the findings from case studies and to reveal important processes responsible for the associated changes. In addition, climate change has the potential to increase the frequency and magnitude of droughts in many parts of the world (Dai, 2012; Cook et al., 2015), further underscoring the importance of understanding the full extent of drought impacts.

In this study we first quantify the impact of historical droughts on air quality, an area largely overlooked in prior investigations of drought impacts, and discuss the possible causes of those impacts. The regional focus is the continental US, where observational records of atmospheric composition are most abundant. The study period is 1990-2014 and the growing season (March-October) when drought has most deleterious impacts on the land and biosphere. We then assess the performance of current climate-chemistry models in capturing the response of surface air pollutants to drought. Future changes in air quality related to increasing drought are estimated.

\section{Data and method}

\subsection{Drought index}

There are many types of drought indices (Heim, 2002). The drought indices most relevant for air quality would be those capable of representing both meteorological (e.g., temperature and precipitation) and land biosphere conditions (e.g., soil moisture, evapotranspiration, vegetation) associated with drought, because air pollution levels are dependent not only on meteorology but also the land-atmosphere interaction. In addition, air pollutants have various characteristic timescales; thus, the relevant drought indices should be able to specify the duration of droughts. Here we chose the standardized precipitation evapotranspiration index (VicenteSerrano et al., 2010) (SPEI) to examine the relationship between drought and air quality. The SPEI is multi-temporal in representing the duration of drought and its formulation is based on water balance approach which explicitly considers the impact of temperature variations on evaporation. To identify the full extent of drought impacts and differentiate drought from normal variability in the hydrological cycle, we used the 1-month SPEI to select droughts lasting more than 1 month. The gridded SPEI datasets are obtained from the global SPEI database (http://sac.csic.es/spei/) with a spatial resolution of $0.5^{\circ} \times 0.5^{\circ}$. While negative SPEI typically indicates drought, a more strict criteria of SPEI $<-1.3$ (the lowest 10th percentile of SPEI) was used here to distinguish drought conditions from non-drought conditions (SPEI between -0.5 and 0.5 ).

To test the robustness of the drought-pollution relationship derived from SPEI, we used the Palmer drought severity index (PDSI) to evaluate this relationship. The PDSI is the most widely used index of meteorological drought in the US and best represents long-term drought ( $\sim 12$ months) (Heim, 2002). Among all forms of PDSI, sc_PDSI_pm is the most updated version with self-calibration and improved formulation of calculating potential evapotranspiration (Dai, 2011). The sc_PDSI_pm dataset (assessed from http://www. cgd.ucar.edu/cas/catalog/climind/pdsi.html) is monthly with a spatial resolution of $2.5^{\circ} \times 2.5^{\circ}$. Drought conditions were identified when sc_PDSI_pm $<-3$.

Figure 1a shows the percent occurrence of drought months (SPEI $<-1.3$ ) over the continental US during the study period. The west US, Great Plains, southeast US, and the southern part of the northeast US clearly stand out as the most drought-prone regions, with extreme droughts occurring $10-25 \%$ of time, ranging between 20 and 40 months during the past 25 years (Fig. 1b). Recent examples of infamous droughts are the 2011 Texas drought (NielsenGammon, 2012), the 2012 Great Plains drought (Hoerling et al., 2014), and the 2014-2015 California drought (Griffin and Anchukaitis, 2014). The PDSI-derived drought occurrence frequency (sc_PDSI_pm $<-3$; Fig. S1 in the Supplement) shows a similar pattern. However, the areas with 
(a) Drought (SPEI <-1.3) frequency

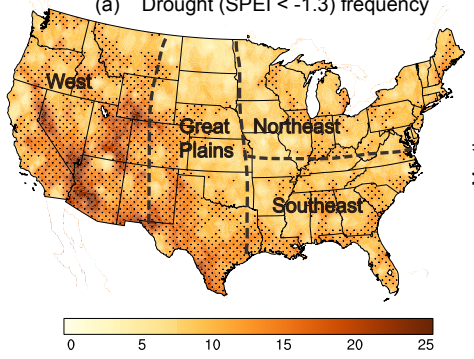

(b) Total month
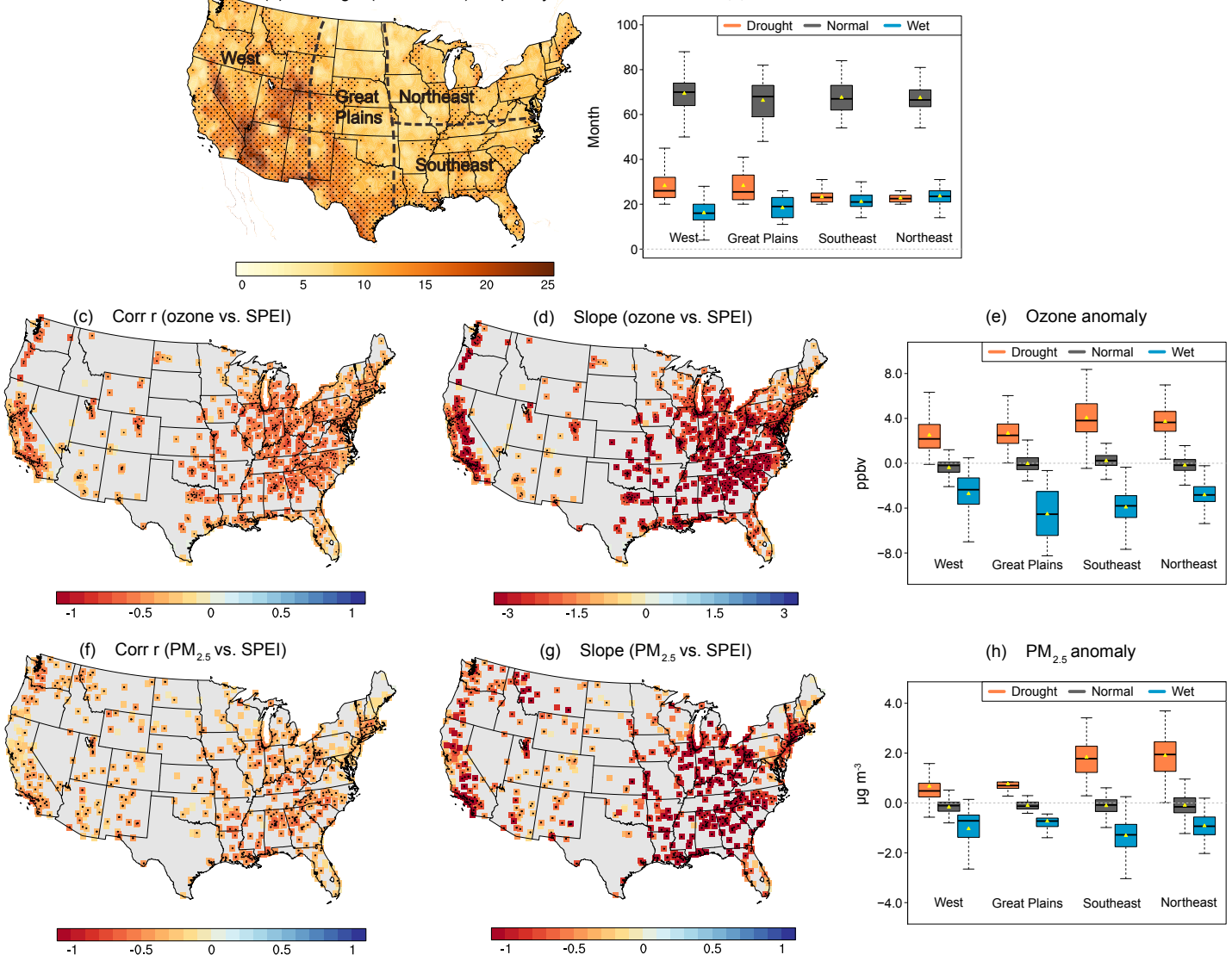

Figure 1. (a) Percentage occurrence of severe drought months (SPEI <-1.3) over the continental US during 1990-2014; black dots indicate drought frequency greater than $10 \%$ and dashed lines show the four geographical regions. Linear regression correlation coefficient $r$ and slope of SPEI with $\mathrm{O}_{3}(\mathbf{c}, \mathbf{d})$ and $\mathrm{PM}_{2.5}(\mathbf{f}, \mathbf{g})$ anomalies at surface sites with data records longer than 5 years; yellow dots indicate regression significance at $95 \%$ confidence level. Box plot comparisons of total months in different dry sectors (b), ozone (e) and $\mathrm{PM}_{2.5}$ anomalies (h) under drought (SPEI $<-1.3)$, normal $(-0.5<$ SPEI $<0.5)$ and wet conditions (SPEI $>1.3$ ) by region; the yellow triangles in the box plot indicate mean values. All the surface data shown in the box plot are restricted to sites with data records longer than 5 years and more than $10 \%$ occurrence of severe drought (SPEI $<-1.3)$.

more than $10 \%$ drought occurrence based on sc_PDSI_pm are much smaller than those based on SPEI (Fig. S1a). This is partly because the two indices represent drought at different timescales (i.e., 1 month for SPEI versus 12 months for sc_PDSI_pm).

\subsection{Air pollution and meteorological data}

Surface concentrations of $\mathrm{PM}_{2.5}$ and maximum daily $8 \mathrm{~h}$ running average (MDA8) ozone over the same period were derived from daily observations collected over more than 2000 surface sites from the US Environmental Protection Agency Air Quality System (EPA-AQS) (http://aqsdr1.epa. gov/aqsweb/aqstmp/airdata/download_files.html), Clean Air Status and Trends Network (CASNET; https://www.epa.gov/ castnet), and the Interagency Monitoring of Protected Visual Environments (IMPROVE) (Malm et al., 1994, http: //views.cira.colostate.edu/) networks. Those daily observa- tions were averaged to monthly means for analysis. The sitespecific SPEI is the SPEI at the grid containing each site. Speciated $\mathrm{PM}_{2.5}$ data were obtained from the Speciation Trend Networks (STN), which is a subset of the EPA AQS with about 180 sites. Sulfate wet depositions were collected from the National Atmospheric Deposition Program (NADP; http://nadp.isws.illinois.edu/). Isoprene concentrations were obtained from the Photochemical Assessment Monitoring Stations (PAMS) network (https://www3.epa.gov/ttnamti1/ pamsdata.html). Surface data at each site were deseasonalized and detrended by removing the 7-year moving averages from the raw data time series for each month to derive the anomalies (see Fig. S2 for an example of data processing). The relationship between SPEI and air pollution anomalies was calculated by linear regression, and the $p$ values are obtained from two-tailed $F$ test. Regional analysis focuses on four geographical divisions of the continental US (Fig. 1a): the west US $\left(128-106^{\circ} \mathrm{W}, 30-50^{\circ} \mathrm{N}\right)$, the Great Plains (106- 
$\left.96^{\circ} \mathrm{W}, 25-50^{\circ} \mathrm{N}\right)$, the southeast US $\left(96-75^{\circ} \mathrm{W}, 25-38^{\circ} \mathrm{N}\right)$, and the northeast US $\left(96-63^{\circ} \mathrm{W}, 38-50^{\circ} \mathrm{N}\right)$.

Fire emissions were obtained from the Global Fire Emission Database $(\mathrm{GFED})$ at a $0.25^{\circ} \times 0.25^{\circ}$ resolution (Giglio et al., 2013; Randerson et al., 2012; Van der Werf et al., 2010; Akagi et al., 2011; http://www.geo.vu.nl/ gwerf/GFED/ GFED4). The spatial impacts of fire smokes can range from a few kilometers to thousands of kilometers depending on the burning area/intensity, injection height, and transport conditions. Fire emissions from nine grid points $(\sim 40 \mathrm{~km})$ around each surface site were sampled to represent the immediate and transported impacts of fires. Temperature and precipitation were obtained from the Climatic Research Unit (CRU, v3.22), which were also used as input data for the global SPEI dataset. Monthly mean cloud fractions from satellite observations were obtained from the Clouds and the Earth's Radiant Energy System (CERES) ISCCP-D1like products at a spatial resolution of $1^{\circ} \times 1^{\circ}$ for the period of 2000 to 2014 (Minnis et al., 2011, https://ceres-tool.larc.nasa.gov/ ord-tool/jsp/ISCCP-D1Selection.jsp). The site-specific meteorological parameters were retrieved from the grid that contains a surface site.

\subsection{Models}

We evaluated the SPEI-pollution relationships simulated by four models from the Atmospheric Chemistry and Climate Model Intercomparison Project (ACCMIP) (Lamarque et al., 2013) that have archived ozone and $\mathrm{PM}_{2.5}$ concentrations: GISS-E2-R, GFDL-AM3, NCAR-CAM3.5, and MIROCCHEM (downloaded from http://browse.ceda.ac.uk/). The ACCMIP experiments were forced with observed greenhouse gas concentrations from historical runs. The four models used the same anthropogenic and biomass burning emissions of ozone and aerosol precursors (Lamarque et al., 2010). While anthropogenic emissions were yearly specific, biomass burning emissions were present at the decadal mean without interannual variations within a specific decade. Natural emissions were not specified, so the models treated natural emissions differently with different responses to drought. For example, isoprene, the most abundant BVOC, is an important precursor of tropospheric ozone and secondary organic aerosols. Only the GISS-E2-R model simulates isoprene emissions as coupled with its meteorology (mostly temperature), thus allowing for isoprene emissions to increase with increasing temperatures. The other three models used prescribed BVOC emissions, thus representing different responses of those emissions to meteorology and climate change. ACCMIP focuses on time-sliced experiments; thus, each model covers different time periods. Model ozone and $\mathrm{PM}_{2.5}$ were deseasonalized and detrended for each time slice experiment in order to remove the effect of changes in anthropogenic emissions.
The model SPEI was calculated using the R package provided by the SPEI developers (https://cran.r-project.org/web/ packages/SPEI/index.html), with simulated precipitation and temperature from each model as inputs. Model temperature was used to estimate reference evapotranspiration using the simplified Thornthwaite (Th) method. The model SPEI was then derived based on logistic-normalized distribution of water deficit, which is the difference between the reference evapotranspiration and model precipitation. Although more accurate estimates of evapotranspiration can be derived using the more complicated Penman-Monteith (PM) method, as used in the historical SPEI database, it requires additional input data not available from the ACCMIP archive. The Thderived SPEI is shown to have tight correlations with the PM-derived SPEI $(r>0.9)$ (Beguería et al., 2014). The relationship of SPEI with air pollution anomalies was derived over all the time periods with available model outputs. To evaluate cloud properties in the model, we used the random overlap approach (Stephens et al., 2004) to calculate the total cloud fraction (CF) (1000 to $10 \mathrm{hPa}$ ) and boundary layer CF $(1000$ to $800 \mathrm{hPa})$, which can be the relevant cloud property for tropospheric ozone photochemical formation and cloud processing of aerosols, respectively. Further details on the model experiments and data processing are listed in Supplement Table S1.

\section{Retrospective analysis}

\subsection{Association between drought and air pollution}

We first derived the general association of surface ozone and $\mathrm{PM}_{2.5}$ with the SPEI at the surface sites. To remove the effects of seasonality and long-term changes in anthropogenic emissions, pollutant concentrations at each surface site were deseasonalized and detrended (as described in Sect. 2.2), and the resulting anomalies were used for analysis. Ozone and $\mathrm{PM}_{2.5}$ anomalies show spatially prevalent negative correlations with the SPEI (Fig. 1), with statistically significant correlations $(p<0.05)$ at $75-88 \%$ of the sites. Since negative SPEI indicates drought, the negative correlations indicate higher pollution levels during drought. The slopes from linear regression span a range of -4.75 to -0.42 for the ozoneSPEI relationship and -2.2 to -0.15 for that of $\mathrm{PM}_{2.5}$-SPEI, with a mean of -2.21 and -0.83 , respectively. The mean regression slope could be interpreted to indicate that an increase in drought severity by 1 standard deviation of the SPEI is associated with an average increase of $2.21( \pm 0.85) \mathrm{ppbv}$ for ozone and $0.83( \pm 0.37) \mu \mathrm{g} \mathrm{m}^{-3}$ for $\mathrm{PM}_{2.5}$ in the US. Both slopes are higher in the east, suggesting larger sensitivities to drought for both ozone (-2.63) and $\mathrm{PM}_{2.5}(-1.0)$ (Fig. 1d and g). Consistently with the SPEI, the PDSI shows statistically significant negative correlations with ozone and $\mathrm{PM}_{2.5}$ anomalies at the majority of the sites (Fig. S1). The correlations with the PDSI are nevertheless weaker, because the 
SPEI is more suitable to present drought at the monthly scale than PDSI.

To further distinguish the drought effects, we aggregated pollutant anomalies from the sites with greater than $10 \%$ occurrence of drought onto three dryness levels: drought (SPEI $<-1.3$ ), normal (SPEI between -0.5 and 0.5 ), and wet (SPEI $>-1.3$ ). The composite comparison of ozone and $\mathrm{PM}_{2.5}$ between those dryness levels is shown in Fig. 1e and h, respectively. Significantly higher levels of both pollutants are found associated with drought across all the regions. The eastern sites show a larger enhancement of ozone and $\mathrm{PM}_{2.5}$ during drought, consistent with the SPEI-pollutant regression slopes being highest in this region. The response of air pollution to drought can be quantified as the difference of pollutants (ozone and $\mathrm{PM}_{2.5}$ ) anomalies during drought relative to their levels during normal conditions. This difference is referred to as enhancement because it is predominantly positive. The average of such enhancements in the US is $3.5 \mathrm{ppbv}$ for ozone and $1.6 \mu \mathrm{g} \mathrm{m}^{-3}$ for $\mathrm{PM}_{2.5}$. Despite regional differences in absolute pollution levels, the relative pollution enhancement during drought is similar across regions at about $8 \%$ for ozone and $17 \%$ for $\mathrm{PM}_{2.5}$ (Fig. S3). The enhancements reported hereafter are all evaluated relative to normal conditions unless noted otherwise; if relative to wet conditions, the magnitudes of the enhancements are typically about a factor of 2 higher.

The composite comparison based on the PDSI is displayed in Fig. S1. Since drought frequency represented by the PDSI is comparatively lower, we chose sites with more than $5 \%$ drought occurrence and 5 years of available surface observations to reduce the spatial sampling bias. The average enhancement associated with drought derived from the PDSI is $2.3 \mathrm{ppb}$ for $\mathrm{O}_{3}$ and $1.2 \mu \mathrm{g} \mathrm{m}^{-3}$ for $\mathrm{PM}_{2.5}$ in the US. The relative enhancement is similar across different regions at about $5 \%$ for ozone and $14 \%$ for $\mathrm{PM}_{2.5}$, smaller but consistent with the results based on the SPEI. Such consistency indicates that the association between air pollution and drought would not depend on one's choice of drought indicator. However, the SPEI is a more suitable index than the PDSI to identify the drought-pollution association at the monthly timescale, and the following analysis is all based on the SPEI.

To test the robustness of the drought-pollution association and explore the temporal characteristics of such association, we performed a composite comparison of air pollutants between drought and normal conditions separately by season (spring, summer, fall) and by drought stage (onset vs. prolonged). Drought onset is defined as the first month when a drought occurs at a given location; if a drought lasts only 1 month, that month is also labeled as onset. A prolonged drought is one when the proceeding month is also a drought. Figure 2 compares the variations of regional ozone and $\mathrm{PM}_{2.5}$ enhancements during drought derived from different temporal sampling approaches. The growing season (March-October) mean enhancement of ozone is close to 3 ppbv in the west and Great Plains, increasing to $3.9 \mathrm{ppbv}$ in the southeast and northeast US. The same spatial gradient is found in the growing season mean enhancement of $\mathrm{PM}_{2.5}$, which increases from a mean of $0.9 \mu \mathrm{g} \mathrm{m}^{-3}$ in the west and Great Plains to $2 \mu \mathrm{g} \mathrm{m}^{-3}$ in the southeast and northeast. Seasonally, all the regions see larger ozone enhancements in summer (June-August) and fall (September-October), with the spring (March-May) enhancement being the smallest. The southeast and the Great Plains have the largest seasonal difference in the response of ozone to drought. Relative to the growing season mean, the ozone enhancements in those region are about $38 \%$ higher in summer/fall and $50 \%$ lower in spring. The seasonal differences of $\mathrm{PM}_{2.5}$ enhancements are not statistically significant for most regions, nor are they coherent between regions, probably due to the complexity in $\mathrm{PM}_{2.5}$ chemical constituents and sources (to be discussed in Sect. 3.3). Only the northeast shows a significantly larger $\mathrm{PM}_{2.5}$ enhancement in summer and significantly smaller enhancement in spring, about $42 \%$ higher and $27 \%$ lower than the growing-season mean, respectively. The seasonal comparison for a given region is based on the same sets of surface sites that experienced droughts in all the seasons; thus, the differences presented above are not caused by sampling differences.

With respect to drought duration (Fig. 2), surface observations in all the regions reveal significantly larger enhancements of both ozone and $\mathrm{PM}_{2.5}$ during prolonged drought months than the onset months, with the only exception of $\mathrm{PM}_{2.5}$ in the northeast which shows a significantly higher enhancement during drought onset. The largest sensitivity to drought duration is found in the southeast, where both ozone and $\mathrm{PM}_{2.5}$ enhancements are higher by up to $50 \%$ during prolonged droughts than the onset. Again, the differences shown for a given region are not caused by sampling differences, as the comparison is based on the same sets of surface sites.

\subsection{Meteorological factors for the drought-pollution association}

Before proceeding with a discussion of the causes of the drought-pollution association, it is useful to present the difference between drought and some meteorological conditions/extremes likely to co-occur with drought that are also associated with higher pollution levels. For example, high ozone is more likely to occur with high temperature and low RH (Hou and Wu, 2016; Zhang and Wang, 2016; Zhang et al., 2017), as well as during heat waves (Filleul et al., 2006), conditions often co-occurring with drought. High$\mathrm{PM}_{2.5}$ events in the US are found to co-occur with high temperature and low wind speed, but not consistently dependent on RH (Tai et al., 2010; Zhang et al., 2017). Stagnation days typically result in high ozone and $\mathrm{PM}_{2.5}$ levels at the surface (Tai et al., 2010; Schnell and Prather, 2016). Compared with those types of weather phenomena and extremes defined on the daily basis, drought has on a longer timescale of at least 
(a) Ozone enhancement
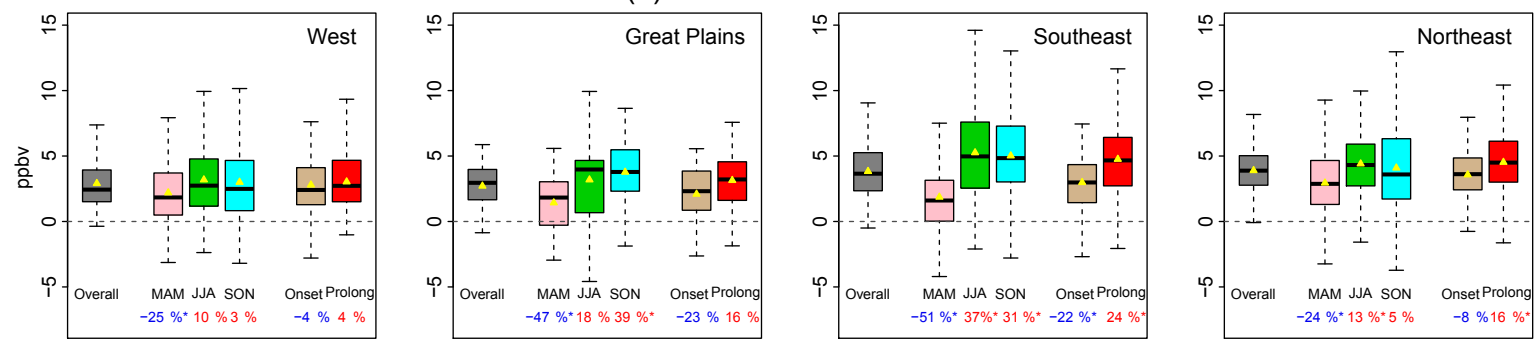

(b) $\mathrm{PM}_{2.5}$ enhancement
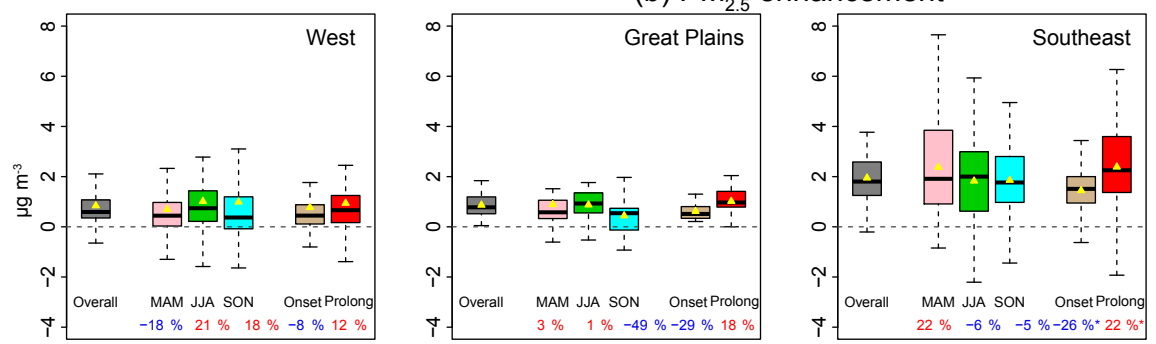

Figure 2. Ozone and $\mathrm{PM}_{2.5}$ enhancements during drought relative to normal conditions at different seasons and different drought stages. The yellow triangles in the box plot indicate mean values. The numbers below each box represent the difference relative to the overall enhancement of the whole growing season (March-October) (grey box), with the asterisks indicating significant differences at $95 \%$ level from the Student $t$ test.

1 week and often monthly. For example, one would not call it a drought if there were no rain for a few days. Drought arises only after a prolonged ( $>$ week) period of precipitation shortage that causes soil to dry up. Therefore, we chose the monthly scale to identify the drought-pollution association, differentiating it from day-to-day variability of meteorology.

Furthermore, drought is a complex extreme not based on individual meteorological parameters (e.g., temperature, humidity) or a simple combination of them. The prominent feature of drought is water deficit in both the atmosphere and the land component (e.g., soil and vegetation), resulting from the combination of precipitation shortage and increasing evapotranspirative water loss driven in part by high temperatures. During the historical drought periods analyzed here, the surface sites were affected with precipitation decreases of up to $50 \%$ regionally and temperature increases of up to $2{ }^{\circ} \mathrm{C}$, as compared to normal conditions (Table S2). Large changes in other meteorological variables are also associated with drought conditions, such as a $10 \%$ decrease in $\mathrm{RH}$, $39 \%$ decrease in cloud fraction, and an increase in incoming solar radiation by $12.4 \mathrm{~W} \mathrm{~m}^{-2}$. Because the timescale of drought is monthly, these meteorological changes are persistent changes on the monthly scale, as opposed to day-to-day variability. As a result, the associated vegetation responses are likely to be more pronounced during drought than those associated with short-term meteorological extremes/events, with important implications for the land-atmosphere exchanges of reactive gases and aerosols.
As discussed above, there are well-established linkages between air quality and some meteorological parameters (e.g., temperature); thus, the drought-pollution association may be partly explained by the effects of drought on these meteorological variables. For example, the co-occurrence of drought with high temperature and low RH is an important reason to explain the pollutant enhancements during drought, especially for surface ozone. However, it would not be feasible to separately quantify the effects of certain meteorological variables on the drought-pollution association, such as temperature, precipitation, and $\mathrm{RH}$, because these variables are all factored in when defining drought. But other meteorological variables might be ruled out as compounding the drought-pollution association. For example, wind speed is a key factor influencing air quality, but not an explicit factor in drought indices. The correlations $(r)$ of monthly mean wind speeds from ERA-Interim reanalysis with the SPEI (Fig. S4) are positive but small for the most part of the US $\left(r^{2}<0.2\right)$, except for the northwest corner and surroundings of the Great Lakes with $r^{2}$ of 0.3-0.4. This suggests that wind speeds might not be an important meteorological factor responsible for the pollution enhancements during drought, except for localized areas where wind-blowing dust would become substantially higher during drought.

In addition, drought months may consist of a larger number of meteorological extremes conducive for high pollutant levels, such as stagnation and heat waves. To understand the pattern and extent of such co-occurrence, we examined the relationships of monthly occurrences 
of stagnation and heat waves with the SPEI at each $0.5^{\circ} \times 0.5^{\circ}$ grid over the study period (Fig. S4). The frequency of stagnation was derived from the NOAA Air Stagnation Index (ASI, https://www.ncdc.noaa.gov/ societal-impacts/air-stagnation/), in which stagnation is defined when surface wind speed smaller than $3.2 \mathrm{~m} \mathrm{~s}^{-1}$, 500 mbar wind smaller than $13 \mathrm{~m} \mathrm{~s}^{-1}$ and no precipitation, following Wang and Angell (1999). Heat waves were defined as two consecutive days with daily mean temperature greater than 90th percentile of the warm-season (May to September) daily mean temperature during 1990-2014, following the method by Anderson and Bell (2011), using ERA-Interim reanalysis (Dee et al., 2011) as inputs. Temporally, both stagnation and heat waves show negative correlations with the SPEI across the US (upper panel of Fig. S4), an indication of more days of these meteorological extremes during drought months, but the squares of these correlations are all below 0.4 , with a typical value of $0.1-0.2$ for the most parts of the US. This suggests that on the monthly scale stagnation and heat waves would typically be able to explain $10-20 \%$ variability in the SPEI, a non-trivial but small fraction. The exceptions are found in isolated locations in the west and southeast, where stagnation could explain up to $40 \%$ of the SPEI variability, and the southern Great Plains with up to $30 \%$ of the SPEI variability explained by heat waves. Stagnation has an overall higher correlation with the SPEI than heat waves, partly because stagnation days by definition exclude precipitation. The lower panel of Fig. S4 shows that stagnation and heat waves have an average 7 and $5 \%$ increase in their frequencies during drought months compared to normal months, although the extent of such increases varies greatly by region. The maximal increase in stagnation frequency during drought is about $15 \%$ in the west, southern Great Plains and southwest, where stagnation tends to occur frequently even during normal conditions. The largest increase in heat waves during drought is about $20 \%$ in the southern Great Plains.

To quantify the compounding effects of stagnation and heat waves on the drought-pollution association, we reevaluated the SPEI-pollutant relationships by applying weights to each pair of SPEI and pollutant anomalies (ozone and $\mathrm{PM}_{2.5}$ ). The weights are given as the percentages of days in each month (regardless of drought or non-drought) that are neither stagnation nor heat wave, assuming the two events are mutually exclusive which would give an upper bound for the weights. For example, a month with none of the two events is given $100 \%$ weight when calculating the SPEI-pollutant correlation and pollutant enhancement, while a month with 15 days of those events has a weight of $50 \%$. The weighted enhancement is calculated as the difference in weightedmean anomalies between drought and normal months. Since the weights are between 0 and 1, the weighting process effectively scales down the magnitude of pollution anomalies in each month, assuming the effects of stagnation and heat waves are linear to their occurrences. Figure 3 compares the original (unweighted) and weighted correlations, regression slopes, and pollution enhancements. The differences in correlation coefficient $(r)$ are mostly smaller than 0.05 in terms of absolute values. The exception is for ozone in the west where the absolute value of the weighted $r$ is increased by $0.1-0.2$, revealing a stronger correlation between SPEI and ozone after accounting for the impacts from stagnation and heat waves. The reason why the direction of the correlation changes after weighting can be either an increase or decrease is because the weights are assigned to both drought and nondrought months. The weighted enhancements of ozone are $30-59 \%$ lower than the original, unweighted values, but remain to be significantly positive. The corresponding reduction for the $\mathrm{PM}_{2.5}$ enhancements is $27-45 \%$. The west and southeast have a larger reduction in the enhancements of both pollutants after weighting, consistent with the fact that these regions show a larger increase in stagnation and heat wave frequencies during drought. The same weighting method can be separately applied to stagnation and heat waves to compare their effects individually (Figs. S5-S6). Stagnation exerts a larger influence on the weighted enhancement in the west and southeast, while heat waves have a larger effect in the Great Plains, consistent with the spatial distribution of their respective occurrences during drought. In all the cases examined here, the weighting does not change the sign or statistical significance of the SPEI-pollutant correlations at all the sites, indicating the covariance of drought with stagnation and heat waves might not be the dominant factor causing the SPEI-pollutant correlations. The weighting, however, reduces the magnitude of ozone and $\mathrm{PM}_{2.5}$ enhancements associated with drought in every region, with an average reduction of $40 \%$ when both events are counted together as weights. This indicates that more frequent stagnation and heat waves could explain up to $40 \%$ of the ozone and $\mathrm{PM}_{2.5}$ enhancements during drought, a significant but not majority factor.

\subsection{Emission/deposition/chemistry factors for the drought-pollution association}

Drought can further affect air quality through perturbations to emissions, deposition, and chemical processes. High temperature conditions during drought will lead to higher production rate of ozone as well as higher emissions of BVOCs (Fuentes et al., 2000; Guenther et al., 2012). Surface observations of isoprene suggest 7-20\% higher concentrations under drought conditions (Table 1; Fig. 4). An exception is a decrease in isoprene during severe drought $($ SPEI $<-2)$ over the southeast and northeast US (Fig. 4), presumably due to shutoff of isoprene emissions when severe water stress causes reduction in carbon sources, lower level of isoprene synthase gene expression, stomata closure, and wilting of vegetation (Pegoraro et al., 2004; Brilli et al., 2007; Seco et al., 2015). Surface $\mathrm{NO}_{2}$ was found to be higher by $0.07-1.26 \mathrm{ppb}(2-9 \%)$, attributable to increased emis- 
(a) Weighted (stagnation + heat wave) changes for ozone
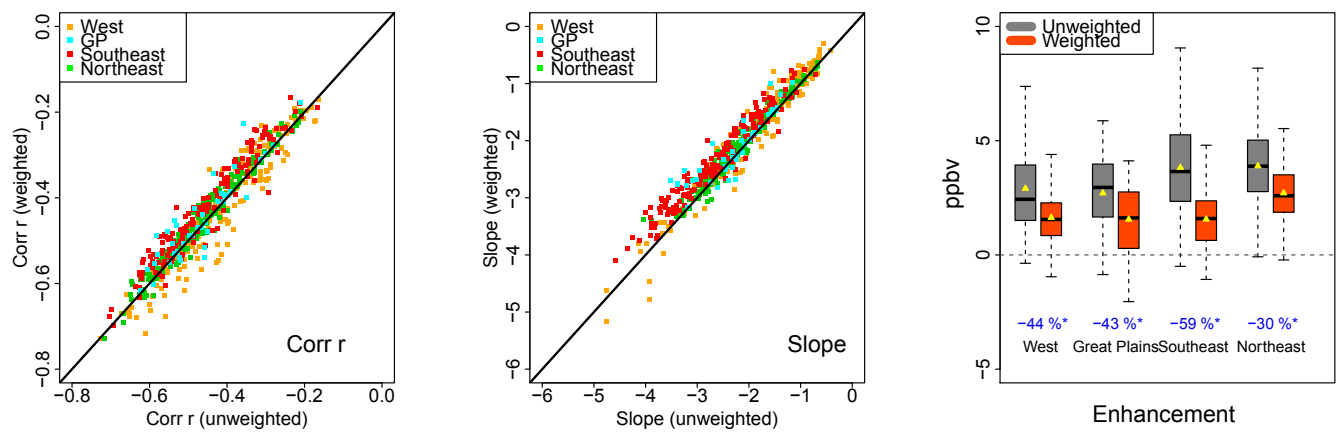

(b) Weighted (stagnation + heat wave) changes for PM,
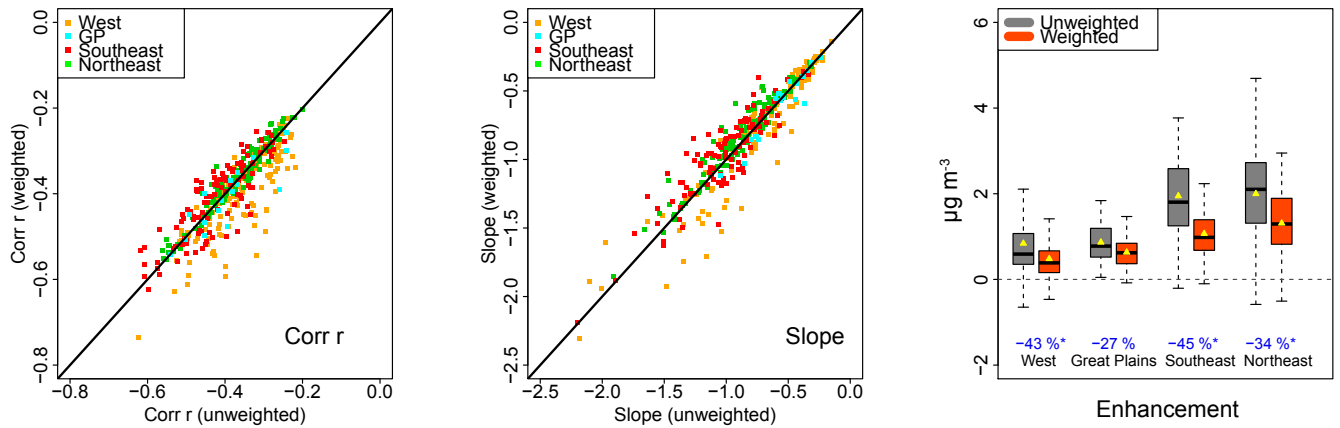

Figure 3. Comparison between the weighted (by frequency of stagnation and heat waves) and unweighted SPEI-pollutants relationship (correlation $r$, left panels; correlation slope, middle panels) and pollutant enhancements (right panels). The upper panels are for ozone and the lower panels for $\mathrm{PM}_{2.5}$. Left and middle panels: the black lines are the $1: 1$ lines and different colors represent different regions. Right panels: the numbers below each box indicate the difference relative to the unweighted enhancements.

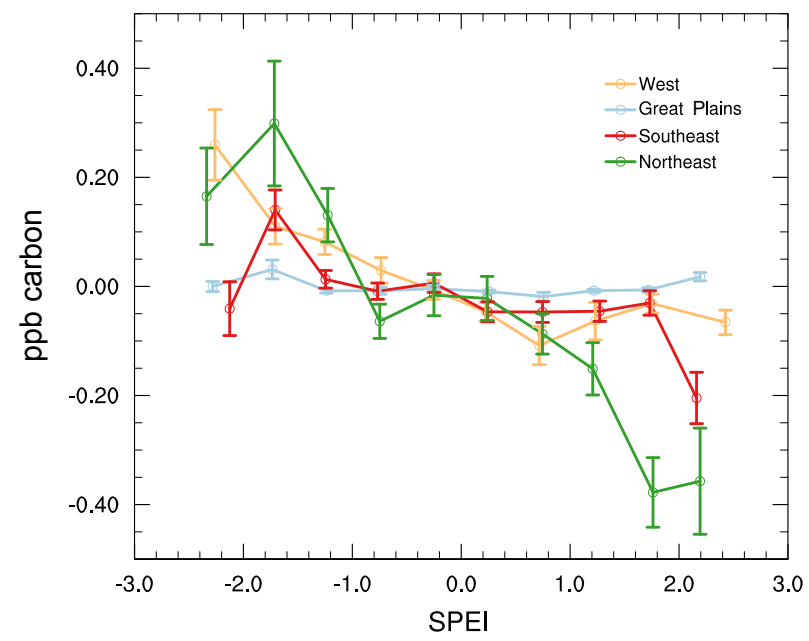

Figure 4. Isoprene anomalies (ppb carbon) derived from the PAMS network at binned SPEI levels over the west US, Great Plains, southeast US, and northeast US. Error bars indicate standard error of the mean.

sions from fires, soils, and possibly the power sector. Precipitation scavenging of air pollutants should be much lower during drought, resulting in higher pollutant concentrations and longer lifetime in the atmosphere. Compiling the scattered measurements by the National Atmospheric Deposition Program, we found a 23-32\% reduction in wet deposition of sulfate during drought (Table 1). In addition, severe drought can potentially lead to elevated surface ozone by reducing the ozone dry deposition to vegetation (Fowler et al., 2009; Kavassalis and Murphy, 2017). A modeling study suggested up to $20 \%$ reductions in ozone dry deposition due to lower stomatal conductance during a drought event in Texas (Huang et al., 2016). However, changes in wet and dry deposition fluxes due to drought are difficult to quantify due to a dearth of deposition measurements.

The enhancements of $\mathrm{PM}_{2.5}$ species during drought are presented in Fig. 5 at a subset of surface sites with speciation measurements. Organic aerosol (OA), sulfate, and dust are major contributors to the overall $\mathrm{PM}_{2.5}$ enhancements. There is a $2-15 \%$ increase in sulfate, attributable in part to reduced wet deposition. While oxidation rate of $\mathrm{SO}_{2}$ increase at high temperatures (Tai et al., 2010), surface $\mathrm{SO}_{2}$ shows a $1-10 \%$ increase during drought, presumably due to reduced dry or wet deposition and higher emissions from fires and electricity generation (Scanlon et al., 2013). Dust enhancements are most significant in the west $(27 \%)$ and the Great Plains $(16 \%)$ due to more semi-arid areas. Significant OA 
Table 1. Changes in the concentrations of atmospheric gaseous compositions and sulfate wet deposition under drought compared to normal conditions. Data are from different measurement networks (see section "Data and method").

\begin{tabular}{|c|c|c|c|c|c|c|c|c|c|}
\hline & & & West & & Great Plains & & Southeast & & Northeast \\
\hline \multirow{3}{*}{$\mathrm{NO}_{2}(\mathrm{ppb})$} & $\mathrm{N}^{\mathrm{a}}$ & & 130 & & 27 & & 81 & & 122 \\
\hline & Diff & 1.26 & $(+9.0 \%)$ & 0.07 & $(+2.3 \%)$ & 0.14 & $(+2.6 \%)$ & 0.46 & $(+3.9 \%)$ \\
\hline & $p$ value $^{\mathrm{b}}$ & & $<0.01$ & & 0.68 & & 0.25 & & $<0.01$ \\
\hline \multirow[t]{3}{*}{$\mathrm{SO}_{2}(\mathrm{ppb})$} & $\mathrm{N}$ & & 66 & & 28 & & 113 & & 290 \\
\hline & Diff & 0.14 & $(+2.6 \%)$ & 0.13 & $(+1.4 \%)$ & 0.29 & $(+10.4 \%)$ & 0.32 & $(+7.3 \%)$ \\
\hline & $p$ value & & 0.05 & & 0.28 & & $<0.01$ & & $<0.01$ \\
\hline \multirow[t]{3}{*}{ Isoprene (ppb carbon) } & $\mathrm{N}$ & & 8 & & 14 & & 28 & & 21 \\
\hline & Diff & 0.21 & $(+11.6 \%)$ & 0.01 & $(+7.0 \%)$ & 0.09 & $(+13.8 \%)$ & 0.36 & $(+19.5 \%)$ \\
\hline & $p$ value & & 0.04 & & 0.60 & & 0.09 & & 0.01 \\
\hline \multirow[t]{3}{*}{ Sulfate wet deposition $\left(\mathrm{kg}\right.$ month $^{-1}$ ) } & $\mathrm{N}$ & & 48 & & 30 & & 47 & & 83 \\
\hline & Diff & -0.62 & $2(-31.7 \%)$ & -1.39 & $9(-26.7 \%)$ & -2.4 & $7(-22.9 \%)$ & -2.9 & $9(-26.2 \%)$ \\
\hline & $p$ value & & $<0.01$ & & $<0.01$ & & $<0.01$ & & $<0.01$ \\
\hline
\end{tabular}

a Number of sites. ${ }^{\mathrm{b}} P$ value derived from the Student $t$ test.

enhancements (12-35\%) are found associated with drought across all the US. Fire emissions of primary OA are 1-3 times higher during drought, explaining a large portion of the OA enhancement (Tables S3-S4). When excluding the fire influences, an increase in the $\mathrm{OA}$ to $\mathrm{BC}$ ratio was found under drought (Fig. S8), indicative of an increase in secondary organic aerosol (SOA) formation. However, routine networks provide only limited classification of OA and cannot fully distinguish the response of SOA to drought from that of total OA.

The above analysis suggests that the ozone and $\mathrm{PM}_{2.5}$ enhancements during drought are largely responses of natural processes from the land biosphere and abnormal atmospheric conditions. To compare the drought-related changes with the effects of anthropogenic emission reductions in the US, we divided the data into two sub-periods: 1990 to 2003 (P1) and 2004 to 2014 (P2). Anthropogenic emissions of $\mathrm{PM}_{2.5}$ and ozone precursors have decreased significantly in the US from $\mathrm{P} 1$ to $\mathrm{P} 2$, for example, by $50 \%$ for $\mathrm{SO}_{2}$ and $32 \%$ for $\mathrm{NO}_{x}$ according to the Air Pollutant Emission Trend Data from the US EPA (EPA, 2016). In spite of this, drought-related enhancements of ozone and $\mathrm{PM}_{2.5}$ are manifested clearly in both periods, with little change in the magnitude of these enhancements between P1 and P2 (Table 2). Under normal conditions, there is a decrease in ozone and $\mathrm{PM}_{2.5}$ from $\mathrm{P} 1$ to $\mathrm{P} 2$ by an average of $1.6 \mathrm{ppbv}$ and $1.8 \mu \mathrm{g} \mathrm{m}^{3}$, respectively, which is attributable to the reductions of US anthropogenic emissions. By comparison, drought-related mean enhancement of ozone exceeds $4 \mathrm{ppbv}$ in both periods and that of $\mathrm{PM}_{2.5}$ is $1.6 \mu \mathrm{g} \mathrm{m}^{3}$. Therefore, the pollutant enhancements associated with droughts do not appear to be affected by the decreasing trend of US anthropogenic emissions, indicating natural processes as the primary cause.

\subsection{Modeled response of air pollutants to drought}

Previous studies suggest that climate models have some skills to predict the variability of drought (Dai, 2012). Indeed, the four models from ACCMIP all reproduce the observed spatial patterns of historical droughts in the US (Fig. S7). Simulated severe droughts (model SPEI $<-1.3$ ) occur $\sim 20 \%$ of the time over the west and southern US, consistent with the observed SPEI. However, the temporal correspondence (i.e., month to month) between model the SPEI and observed SPEI dataset is weak, largely due to the models' deficiency in simulating temporal variability of precipitation. This weak correlation, however, is not expected to affect the evaluation of simulated pollution responses to drought, because we used the model SPEI to derive the SPEI-pollutants relationships from each model.

The models vary greatly in their ability of predicting the drought-pollutants relationships. With respect to surface ozone, all the models are able to capture its negative correlation with SPEI over most of the US (Fig. 6), as they all predict some levels of increase in ozone production driven by higher temperatures during drought (Fig. S9). However, the simulated slopes and magnitude of ozone enhancement are less than half of the observed values in many regions, suggesting a lack of full representation of the drought effects. The GISS-E2-R model, which is the only model that includes interactive isoprene emissions with model temperature, reproduces the observed isoprene increases. This allows the model to simulate ozone enhancements resulting from stronger isoprene emissions (Schnell et al., 2016), and thus the GISS model simulates the greater SPEI-ozone slope as compared to other models (Fig. 6). In spite of lacking the interactive isoprene emissions, the MICRO-CHEM model shows higher ozone enhancements than other models be- 
(a)

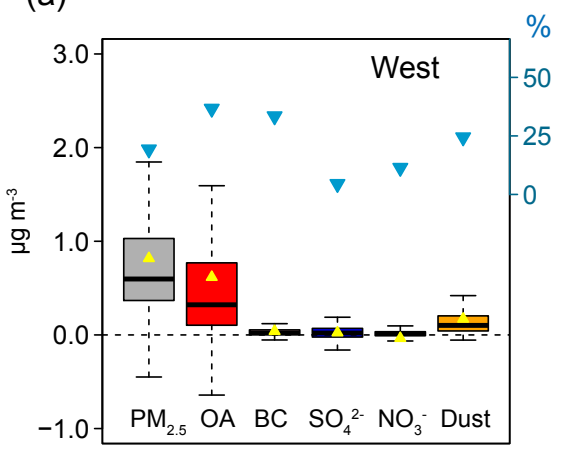

(c)

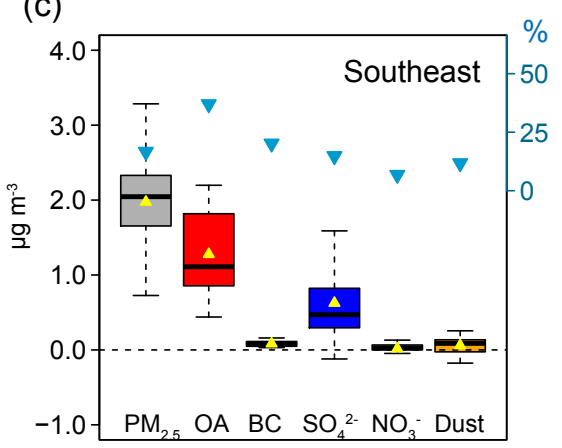

(b)

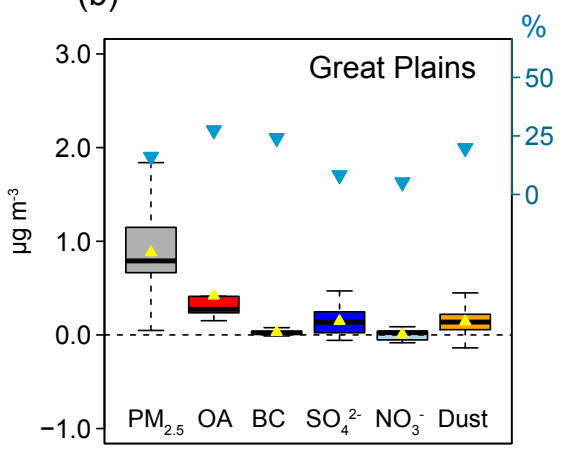

(d)

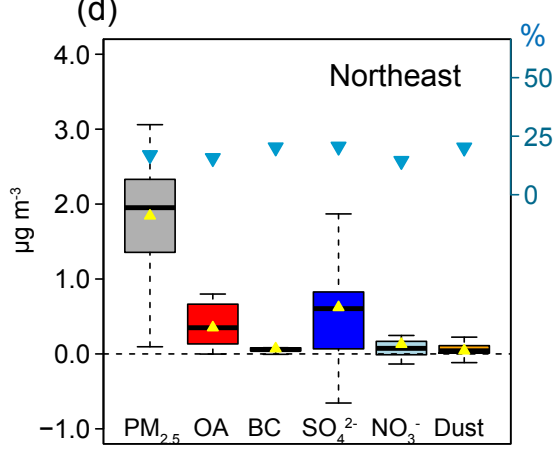

Figure 5. Box plot of anomalies in $\mathrm{PM}_{2.5}$ speciation during drought (SPEI $\left.<-1.3\right)$ compared to normal $(-0.5<\mathrm{SPEI}<0.5)$ conditions for the west US (a), Great Plains (b), southeast US(c), and northeast (d) US. The yellow triangles indicate mean values and blue triangles indicate relative changes (right $y$ axis).

Table 2. Changes in the concentrations of ozone and $\mathrm{PM}_{2.5}$ at two periods under drought compared to normal conditions.

\begin{tabular}{lrrrrrrr}
\hline & \multicolumn{2}{c}{ P1 (1990-2003) } & \multicolumn{2}{c}{ P2 (2004-2014) } & P2 minus P1 \\
& Drought & Normal & Diff & Drought & Normal & Diff & Normal \\
\hline \multicolumn{7}{c}{ Ozone (ppbv) } \\
\hline West & 56.61 & 51.58 & 5.03 & 53.19 & 49.15 & 4.04 & 2.43 \\
Great Plains & 51.64 & 47.23 & 4.41 & 52.23 & 47.75 & 4.48 & -0.52 \\
Southeast & 51.98 & 47.01 & 4.97 & 49.03 & 44.75 & 4.28 & 2.26 \\
Northeast & 51.64 & 46.43 & 5.21 & 48.19 & 44.23 & 3.96 & 2.20 \\
Average & 52.97 & 48.06 & 4.91 & 50.66 & 46.47 & 4.19 & 1.59 \\
\hline & & \multicolumn{7}{c}{$\mathrm{PM}_{2.5}\left(\mu \mathrm{g} \mathrm{m}^{3}\right)$} \\
West & 6.57 & 5.56 & 1.01 & 5.84 & 4.74 & 1.10 & 0.82 \\
Great Plains & 7.69 & 6.22 & 1.47 & 6.86 & 5.81 & 1.05 & 0.41 \\
Southeast & 15.98 & 14.19 & 1.79 & 13.79 & 11.45 & 2.34 & 2.74 \\
Northeast & 16.37 & 14.25 & 2.12 & 12.67 & 10.94 & 1.73 & 3.31 \\
Average & 11.65 & 10.06 & 1.60 & 9.79 & 8.24 & 1.56 & 1.82 \\
\hline
\end{tabular}

cause it simulates the largest increase in ozone production caused by drought, presumably due to a larger sensitivity of ozone to temperature. Drought perturbation of the land biosphere would lead to reductions in the ozone dry deposition sink and hence higher ozone enhancements. For example, a model sensitivity study by Lin et al. (2017) showed that re- ducing ozone dry deposition velocity by $35 \%$ in the GFDLAM3 model during the severe North American drought of 1988 would lead to $10 \mathrm{ppbv}$ greater ozone enhancements than a simulation with constant dry deposition velocity. However, all the ACCMIP models examined here simulate small changes in ozone dry deposition (-3-5\%) during drought. 
(a) Model slope (ozone vs. SPEI)
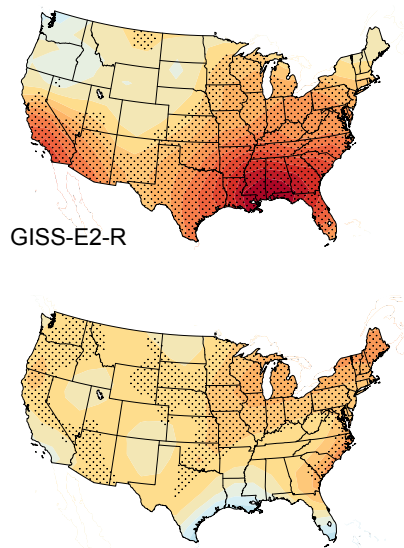

NCAR-CAM3.5
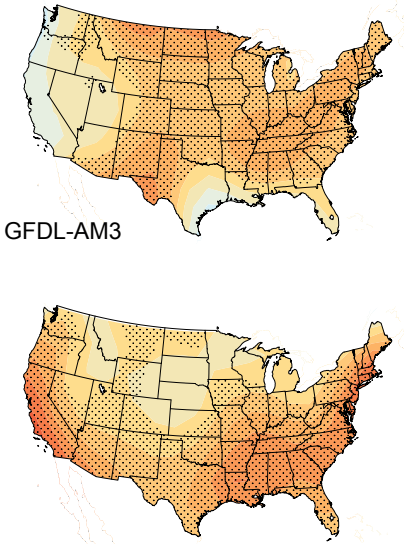

MIROC-CHEM (b) Model ozone changes under drought

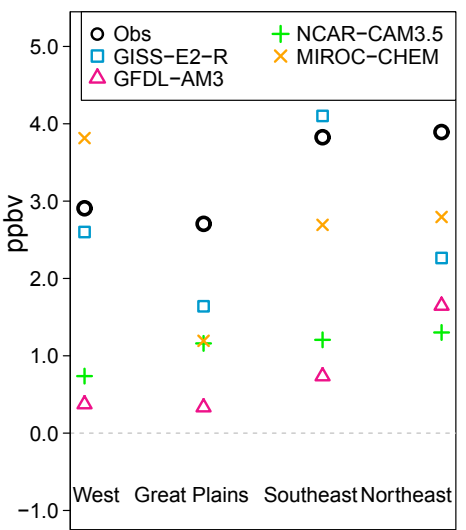

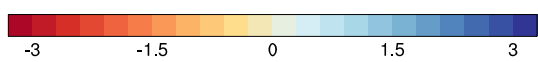

Figure 6. Linear regression slope between model-derived SPEI and simulated ozone from GISS-E2-R, GFDL-AM3, NCAR-CAM3.5 and MIROC-CHEM model (a). Black dots represent regression significance at $95 \%$ confidence level. Note the color bar of (a) is the same as in Fig. 1c. Comparison for the observed (black circle) and simulated changes (colored symbols) in ozone (b) under drought (SPEI $<-1.3$ ) compared to normal $(-0.5<\mathrm{SPEI}<0.5)$ conditions by region.

(a) Model slope $\left(\mathrm{PM}_{2.5}\right.$ vs. SPEI)
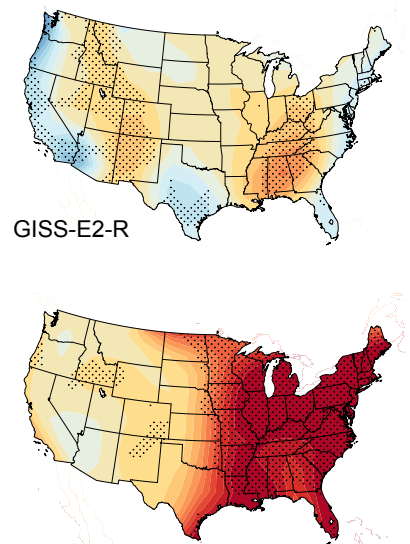

NCAR-CAM 3.5
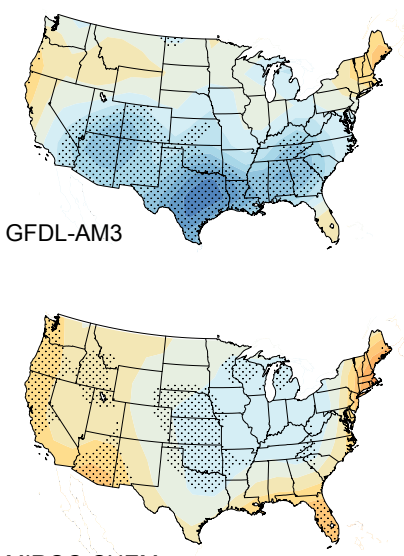

MIROC-CHEM (b) Model $\mathrm{PM}_{2.5}$ changes under drought

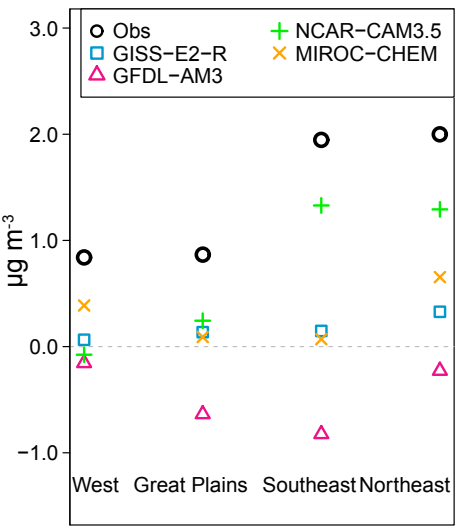

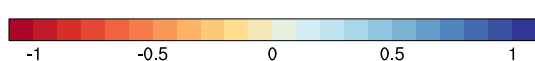

Figure 7. Linear regression slope between model-derived SPEI and simulated PM 2.5 from GISS-E2-R, GFDL-AM3, NCAR-CAM3.5 and MIROC-CHEM model (a). Black dots represent regression significance at $95 \%$ confidence level. Note the color bar of (a) is the same as in Fig. 1e. Comparison for the observed (black circle) and simulated changes (colored symbols) in $\mathrm{PM}_{2.5}$ (b) under drought (SPEI $<-1.3$ ) compared to normal $(-0.5<\mathrm{SPEI}<0.5)$ conditions by region.

The models are less skillful in reproducing the effects of drought on $\mathrm{PM}_{2.5}$ (Fig. 7). All the models incorrectly predict a decrease in $\mathrm{PM}_{2.5}$ under drought conditions and hence a positive $\mathrm{PM}_{2.5}$-SPEI relationship for many regions in the US, whereas this relationship is clearly negative in the observations across all the regions. For the few regions where some models are correct about the direction of the $\mathrm{PM}_{2.5}$ change (e.g., the western US by GISS-E2-R and eastern US by NCAR-CAM3.5), the magnitude of the $\mathrm{PM}_{2.5}$ change is less than $70 \%$ of that observed.

The model response is primarily driven by a ubiquitous and excessive decrease in sulfate under drought conditions caused by large reductions of sulfate production in clouds ( -22 to $-73 \%$ ) (Figs. S10-S11). In contrast, only 14-34\% of the sites in the west and the Great Plains show a decrease in sulfate during drought. The model deficiency in sul- 
(a) Slope between SPEI and total cloud fraction

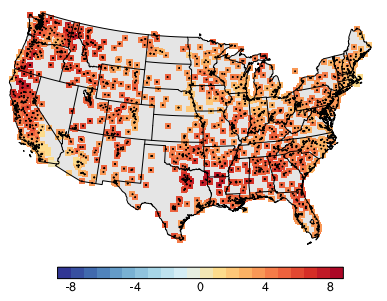

Observation (ISCCP-D1like)

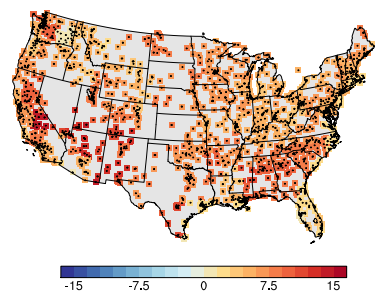

Model (GISS-E2-R)

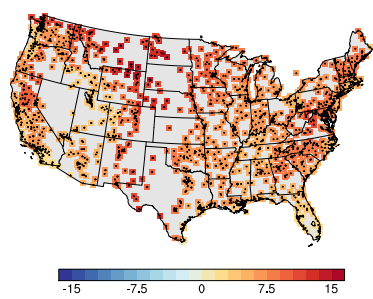

Model (GFDL-AM3)

(b) Slope between SPEI and boundary layer cloud fraction

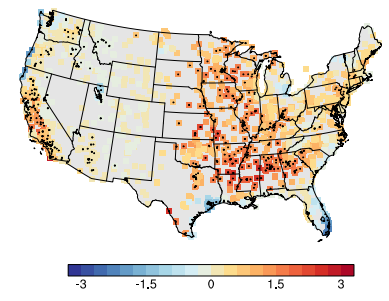

Observation (ISCCP-D1like)

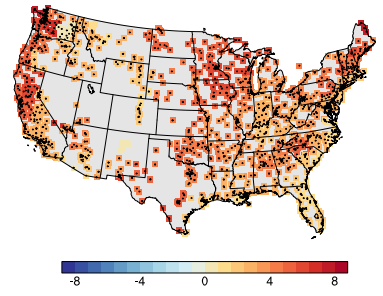

Model (GISS-E2-R)

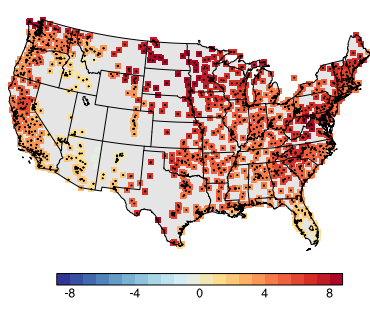

Model (GFDL-AM3)

Figure 8. Slopes from linear regression between SPEI and (a) total and (b) boundary layer cloud fractions from the ISCCP satellite observations (left), GISS-E2-R (middle), and GFDL-AM3 model (right).

fate can be explained by their underestimate of low-altitude cloud fraction at higher temperatures (Shen et al., 2017). This bias would lead to an underestimate of sulfate production as well as SOA-processing in clouds during drought (i.e., hightemperature conditions), which could outweigh the aerosol deposition decrease. Figure 8 compares the satellite-derived sensitivity of total and boundary-layer CF to drought severity with that simulated by the GISS and GFDL model, which are the only ACCIMP models that archived layer-specific CF. For the boundary layer $\mathrm{CF}$ which should be more relevant for in-cloud processing of aerosols, the observed sensitivity averages about 0.51 per unit increase in SPEI, while the GISS and GFDL model shows a sensitivity of 4.37 and 3.41, respectively, about a factor of 8 higher than the observed value. The models also overestimate the sensitivity of total CF to drought, but to a less extent. Another important aspect of model deficiencies is that they all underestimate the OA enhancements in every region. Simulated OA changes primarily result from reduced wet deposition $(\sim 40 \%)$, lacking important contributions from changing BVOC emissions, fires, or chemistry (Figs. S10-S11) as suggested by observations.

In summary, the model deficiencies suggest a lack of mechanistic understanding of natural processes of importance to atmospheric composition and/or their perturbations by drought, although attribution of the underlying causes would require climate-chemistry model sensitivity experiments, which is outside the scope of the present study. Emissions, deposition, and chemistry are the most important aspects of model configurations affecting the drought- pollutants relationship. Since natural emissions were not specified, the ACCIMP models treated natural emissions differently, which is a key factor in the different performance between models. Using the observed SPEI-pollutants relationship as a diagnostic, we found that the model with interactive isoprene emissions (e.g., the GISS model) has a better ability to simulate the SPEI-ozone relationship, indicating the importance of drought effects on BVOC emissions. With regard to deposition, all the models simulate some levels of decreasing wet deposition during drought, but dry deposition is largely insensitive to drought due to the lack of drought effects on the properties of the land and biosphere. The overestimate of the dry deposition sink during drought may be another reason behind the models' deficiency in underestimating the drought-pollutants relationship. Lastly, all the models overestimate the sulfate reduction but at the same time underestimate the OA increase during drought. Both problems might be caused by the model misrepresentation of cloud sensitivity to changing drought severity, although the OA bias could also be caused by uncertainties of fire and BVOC emissions in the model.

\section{Future changes in drought and adverse impacts on air quality}

To circumvent the model deficiencies, the effects of future increases of drought on air quality were estimated by extrapolating their present-day relationships from observations to 
(a) SPEl change (2100 minus 2000)
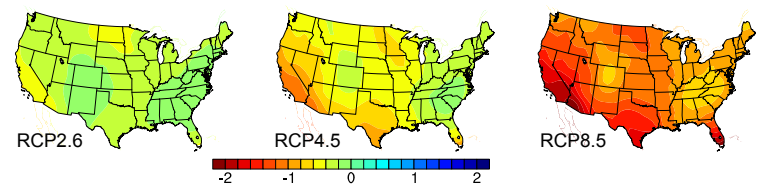

(b) Ozone change (2100 minus 2000)

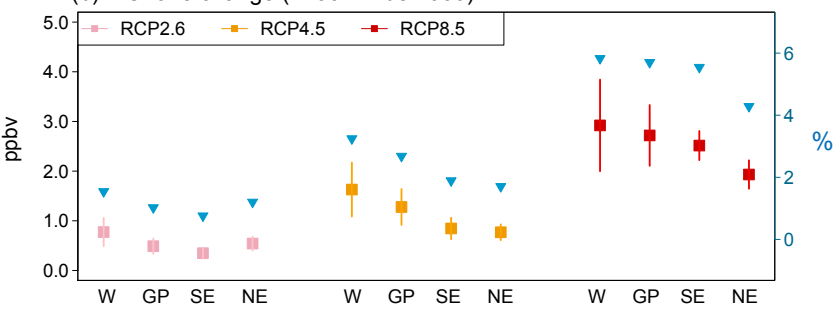

(c) PM change (2100 minus 2000)

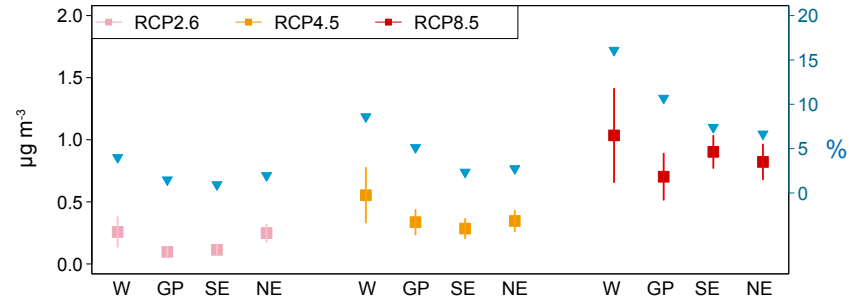

Figure 9. Predicted changes in SPEI between 2100 (2080-2099 average) and 2000 (1990-2005 average) by region under three RCP scenarios (a) from mean of four models (GISS-E2-R, GFDL-CM3, CCSM4 and MIROC-ESM-CHEM) and the estimated changes in surface ozone (b) and $\mathrm{PM}_{2.5}$ (c) resulting from the SPEI changes alone. The four points in each RCP scenario represent the west US, Great Plains, southeast US, and northeast US. Error bar represents 0.5 standard deviation. Blue triangles indicate the mean percentage changes relative to the 2000 conditions (right $y$ axis).

model projected drought occurrences under future warming scenarios. Projected changes in SPEI from the present to future climate were derived from the outputs of the four ACCMIP models (i.e., GISS-E2-R, GFDL-CM3, CCSM4, and MIROC-ESM-CHEM) archived by the Coupled Model Intercomparison Project Phase 5 (CMIP5) (Taylor et al., 2012). The CMIP5 historical runs cover the period from 1850 to near present, and are forced with observed changes in atmospheric composition with evolving land cover. The future projection runs span from 2006 to 2300 , forced with specified concentrations of certain atmospheric constituents defined in three representative concentration pathway (RCP) scenarios (Moss et al., 2010): RCP 2.6 (low-mitigation emission scenario), RCP 4.5 (mid-range mitigation emission scenario) and RCP 8.5 (high-emission scenario). Changes in future drought conditions compared to the present are defined as the 2100 SPEI (2080-2099 mean) minus its value in 2000 (1990-2005 mean).

Figure 9a shows the projection of SPEI in the US by 2100 (2080-2099 mean) under different RCPs that are derived from the mean of the four models from the CMIP5 outputs. Drought risks are projected to increase with warming scenarios over all parts of the US, with the largest increases in the west and the Great Plains, consistent with previous projections (Cook et al., 2015). These projected SPEI changes (2100 minus 2000), when multiplied by the presentday relationship between SPEI and air quality derived from observations (see Fig. 1), suggests a $0.3-3.0 \mathrm{ppb}(1-6 \%$ ) increase in surface ozone and $0.1-1.0 \mu \mathrm{g} \mathrm{m}^{-3}(1-16 \%)$ increase in $\mathrm{PM}_{2.5}$ in the US in 2100 as a result of increasing drought alone under different RCPs (Fig. 7b-c). The increase in ozone and $\mathrm{PM}_{2.5}$ are largest in the west. The maximum increase is $14 \%$ for ozone and $41 \%$ for $\mathrm{PM}_{2.5}$ under the extreme warming scenario (RCP 8.5), significantly higher than the present-day effects. While this extrapolation-based projection may not be reliable quantitatively, it suggests a significant climate change penalty on air quality through drought, which has been overlooked before and poses a new challenge for air quality managers.

\section{Discussion}

The retrospective analysis of observations demonstrates that past droughts have been associated with significant deterioration of air quality through natural processes, resulting in potentially large tolls on public health that have not been considered in previous impact analysis of drought. The land biosphere plays a key role in mediating drought-related changes in atmospheric chemistry. The magnitude of the land biosphere response is largely dependent on concurrent changes in solar irradiance, temperature and water at different levels of drought severity and duration. More sunlight and higher temperatures may outweigh some levels of water stress, resulting in enhanced BVOC emissions through leaf biochemistry, vapor pressure difference and underlying metabolism processes (Fuentes et al., 2000). However, extreme and/or prolonged drought conditions with severe water stress coupled with very high temperatures can affect the activity of enzyme and health of the plants, therefore leading to reductions in BVOC emissions. More comprehensive understanding of the land biosphere responses is required to quantify the impact of land biosphere to atmospheric compositions under different drought conditions. In addition to changing BVOC emissions, reduced aerosol water content under drought conditions can perturb aqueous-phase formation of SOA from BVOCs, but the impact is not clear (Gilardoni et al., 2016). Changes in anthropogenic emissions under drought conditions are also uncertain. Local land use type and water management policy can significantly affect human reactions to drought. Furthermore, the interaction between anthropogenic emissions and natural responses further compound the drought effect, as anthropogenic emitted gases and aerosols can affect the oxidation and partitioning processes of SOA from BVOCs (Hoyle et al., 2011; Xu et al., 2015). 
Changes in the land biosphere and atmospheric compositions, including gases and aerosols, can provide feedbacks to the climate through radiative effects and cloud interactions. Reductions in vegetation cover affect surface albedo and dust emissions, resulting in enhanced surface temperatures, intensification of drought conditions and geographical shift of drought pattern (Cook et al., 2009). Increasing wildfire activity and fire-emitted aerosols alter the regional energy budget and circulation, which lead to reduced precipitation thus further enhancing drought severity and vulnerability of ecosystem towards wildfires (Bevan et al., 2009; Tosca et al., 2010; Hodnebrog et al., 2016). Improvements in climate-chemistry models are thus imperative to facilitate better prediction of atmospheric composition changes due to changes in drought and improved understanding of the associated feedbacks of composition changes to climate and drought itself.

The observational analysis presented here indicates significant changes in air pollutants under drought conditions. However, it is not sufficient to quantify the full extent of the cascading effects of drought on the complex chemistry of ozone and SOA, which would require more targeted measurements providing for example more classification of organic materials and modeling at the process level. Uncertainties exist in the model assessment since we are using a single version of a simulation for each model and the study period is relatively short and may not represent the full simulation results. Nonetheless, both observations and the model indicate the important role of the land biosphere and atmospheric conditions in regulating pollutant levels under drought conditions. Future air quality management should consider the adverse effects from increasing drought risks.

Data availability. All datasets used in this study are publicly accessible. The observed and modeled SPEI-pollutants correlation data are accessible online at https://dataverse.harvard.edu/dataset.xhtml? persistentId=doi:10.7910/DVN/APVGJB.

\section{The Supplement related to this article is available online at https://doi.org/10.5194/acp-17-12827-2017- supplement.}

Author contributions. YW and YX conceived the research idea. YX and WD performed the analysis and YW wrote the initial draft of the paper. All authors contributed to the interpretation of the results and the preparation of the manuscript.

Competing interests. The authors declare that they have no conflict of interest.

Acknowledgements. We thank the individuals and groups involved in making observations at IMPROVE, US EPA, CASNET, NADP, and PAMS networks as well as in preparing the SPEI, PDSI, GFED, ASI, CRU, ERA-Interim, and ISCCP-D1like database. We thank the modeling groups that participate in ACCMIP and CMIP5 for producing the model outputs and making them available. This work was supported in part by the National Key Basic Research Program of China (2013CB956603 and 2014CB441302). Jun Wang acknowledges the support from the NASA Aura Science program (grant no. NNX14AG01G, managed by Ken Jucks), Applied Science Program (grant no. NNX15AC28A, managed by John Haynes), and ACMAP program (grant no. NNX15AC30G, managed by Richard Eckman).

Edited by: Alex B. Guenther

Reviewed by: three anonymous referees

\section{References}

Akagi, S. K., Yokelson, R. J., Wiedinmyer, C., Alvarado, M. J., Reid, J. S., Karl, T., Crounse, J. D., and Wennberg, P. O.: Emission factors for open and domestic biomass burning for use in atmospheric models, Atmos. Chem. Phys., 11, 4039-4072, https://doi.org/10.5194/acp-11-4039-2011, 2011.

Allen, R. J., Landuyt, W., and Rumbold, S. T.: An increase in aerosol burden and radiative effects in a warmer world, Nature Climate Change, 6, 269-274, https://doi.org/10.1038/nclimate2827, 2015.

Anderson, G. B. and Bell, M. L.: Heat Waves in the United States: Mortality Risk during Heat Waves and Effect Modification by Heat Wave Characteristics in 43 U.S. Communities, Environ. Health Perspect., 119, 210-218, https://doi.org/10.1289/ehp.1002313, 2011.

Arnell, N. W.: Climate change and global water resources: SRES emissions and socio-economic scenarios, Global Environ. Chang., 14, 31-52, 2004.

Beguería, S., Vicente-Serrano, S. M., Reig, F., and Latorre, B.: Standardized precipitation evapotranspiration index (SPEI) revisited: parameter fitting, evapotranspiration models, tools, datasets and drought monitoring, Int. J. Climatol., 34, 3001-3023, 2004.

Bevan, S. L., North, P. R., Grey, W. M., Los, S. O., and Plummer, S. E. Impact of atmospheric aerosol from biomass burning on Amazon dry season drought, J. Geophys. Res.-Atmos., 114, https://doi.org/10.1029/2008JD011112, 2009.

Brilli, F., Barta, C., Fortunati, A., Lerdau, M., Loreto, F., and Centritto, M.: Response of isoprene emission and carbon metabolism to drought in white poplar (Populus alba) saplings, New Phytol., 175, 244-254, 2007.

Cook, B. I., Miller, R. L., and Seager, R.: Amplification of the North American "Dust Bowl" drought through human-induced land degradation, P. Natl. Acad. Sci. USA, 106, 4997-5001, 2009.

Cook, B. I., Ault, T. R., and Smerdon, J. E.: Unprecedented 21st century drought risk in the American Southwest and Central Plains, Science Advances, 1, e1400082, https://doi.org/e1400082, 2015.

Dai, A.: Characteristics and trends in various forms of the Palmer Drought Severity Index during 1900-2008, J. Geophys. Res.Atmos., 116, https://doi.org/10.1029/2010JD015541, 2011. 
Dai, A.: Increasing drought under global warming in observations and models, Nature Climate Change, 3, 52-58, https://doi.org/10.1038/nclimate1633, 2012.

Davidson, E. A., Nepstad, D. C., Ishida, F. Y., and Brando, P. M.: Effects of an experimental drought and recovery on soil emissions of carbon dioxide, methane, nitrous oxide, and nitric oxide in a moist tropical forest, Glob. Change Biol., 14, 2582-2590, 2008.

Dawson, J. P., Adams, P. J., and Pandis, S. N.: Sensitivity of $\mathrm{PM}_{2.5}$ to climate in the Eastern US: a modeling case study, Atmos. Chem. Phys., 7, 4295-4309, https://doi.org/10.5194/acp-7-42952007, 2007.

Dee, D. P., Uppala, S. M., Simmons, A. J., Berrisford, P., Poli, P., Kobayashi, S., Andrae, U., Balmaseda, M. A., Balsamo, G., Bauer, P., Bechtold, P., Beljaars, A. C. M., van de Berg, L., Bidlot, J., Bormann, N., Delsol, C., Dragani, R., Fuentes, M., Geer, A. J., Haimberger, L., Healy, S. B., Hersbach, H., Hólm, E. V., Isaksen, L., Kållberg, P., Köhler, M., Matricardi, M., McNally, A. P., Monge-Sanz, B. M., Morcrette, J.-J., Park, B.-K., Peubey, C., de Rosnay, P., Tavolato, C., Thépaut, J.-N., and Vitart, F.: The ERA-Interim reanalysis: configuration and performance of the data assimilation system, Q. J. Roy. Meteor. Soc., 137, 553-597 2011.

Filleul, L., Cassadou, S., Médina, S., Fabres, P., Lefranc, A., Eilstein, D., Le Tertre, A., Pascal, L., Chardon, B., Blanchard, M., Declercq, C., Jusot, J.-F., Prouvost, H., and Ledrans, M.: The Relation Between Temperature, Ozone, and Mortality in Nine French Cities During the Heat Wave of 2003, Environ. Health Persp., 114, 1344-1347, https://doi.org/10.1289/ehp.8328, 2006.

Fowler, D., Pilegaard, K., Sutton, M. A., Ambus, P., Raivonen, M., Duyzer, J., Simpson, D., Fagerli, H., Fuzzi, S., Schjoerring, J. K., Granier, C., Neftel, A., Isaksen, I. S. A., Laj, P., Maione, M., Monks, P. S., Burkhardt, J., Daemmgen, U., Neirynck, J., Personne, E., Wichink-Kruit, R., Butterbach-Bahl, K., Flechard, C., Tuovinen, J. P., Coyle, M., Gerosa, G., Loubet, B., Altimir, N., Gruenhage, L., Ammann, C., Cieslik, S., Paoletti, E., Mikkelsen, T. N., Ro-Poulsen, H., Cellier, P., Cape, J. N., Horváth, L., Loreto, F., Niinemets, Ü., Palmer, P. I., Rinne, J., Misztal, P., Nemitz, E., Nilsson, D., Pryor, S., Gallagher, M. W., Vesala, T., Skiba, U., Brüggemann, N., Zechmeister-Boltenstern, S., Williams, J., O'Dowd, C., Facchini, M. C., de Leeuw, G., Flossman, A., Chaumerliac, N., and Erisman, J. W.: Atmospheric composition change: ecosystems-atmosphere interactions, Atmos. Environ., 43, 5193-5267, 2009.

Forouzanfar, M. H., Alexander, L., Anderson, H. R., Bachman, V. F., Biryukov, S., Brauer, M., Burnett, R., Casey, D., Coates, M. M., and Cohen, A.: Global, regional, and national comparative risk assessment of 79 behavioural, environmental and occupational, and metabolic risks or clusters of risks in 188 countries, 1990-2013: a systematic analysis for the Global Burden of Disease Study 2013, The Lancet, 386, 2287-2323, 2015.

Fuentes, J. D., Gu, L., Lerdau, M., Atkinson, R., Baldocchi, D., Bottenheim, J., Ciccioli, P., Lamb, B., Geron, C., and Guenther, A.: Biogenic hydrocarbons in the atmospheric boundary layer: a review, B. Am. Meteorol. Soc., 81, 1537-1575, 2000.

Giglio, L., Randerson, J. T., and Werf, G. R.: Analysis of daily, monthly, and annual burned area using the fourth-generation global fire emissions database (GFED4), J. Geophys. Res.Biogeo., 118, 317-328, 2013.
Gilardoni, S., Massoli, P., Paglione, M., Giulianelli, L., Carbone, C., Rinaldi, M., Decesari, S., Sandrini, S., Costabile, F., and Gobbi, G. P.: Direct observation of aqueous secondary organic aerosol from biomass-burning emissions, P. Natl. Acad. Sci. USA, 113, 10013-10018, 2016.

Griffin, D. and Anchukaitis, K. J.: How unusual is the 2012-2014 California drought?, Geophys. Res. Lett., 41, 9017-9023, 2014.

Guenther, A. B.: Bidirectional exchange of volatile organic compounds, Review and Integration of Biosphere-Atmosphere Modelling of Reactive Trace Gases and Volatile Aerosols, Springer Netherlands, 107-113, 2015.

Guenther, A. B., Jiang, X., Heald, C. L., Sakulyanontvittaya, T., Duhl, T., Emmons, L. K., and Wang, X.: The Model of Emissions of Gases and Aerosols from Nature version 2.1 (MEGAN2.1): an extended and updated framework for modeling biogenic emissions, Geosci. Model Dev., 5, 1471-1492, https://doi.org/10.5194/gmd-5-1471-2012, 2012.

Heim, R. R.: A review of twentieth-century drought indices used in the United States, B. Am. Meteorol. Soc., 83.8, 1149-1165, 2002.

Hodnebrog, Ø., Myhre, G., Forster, P. M., Sillmann, J., and Samset, B. H.: Local biomass burning is a dominant cause of the observed precipitation reduction in southern Africa, Nature Communications, 7, https://doi.org/10.1038/ncomms11236, 2016.

Hoerling, M., Eischeid, J., Kumar, A., Leung, R., Mariotti, A., Mo, K., Schubert, S., and Seager, R.: Causes and predictability of the 2012 Great Plains drought, B. Am. Meteorol. Soc., 95, 269-282, 2014.

Hou, P. and Wu, S.: Long-term Changes in Extreme Air Pollution Meteorology and the Implications for Air Quality, Scientific reports, 6, https://doi.org/10.1038/srep23792, 2016.

Hoyle, C. R., Boy, M., Donahue, N. M., Fry, J. L., Glasius, M., Guenther, A., Hallar, A. G., Huff Hartz, K., Petters, M. D., Petäjä, T., Rosenoern, T., and Sullivan, A. P.: A review of the anthropogenic influence on biogenic secondary organic aerosol, Atmos. Chem. Phys., 11, 321-343, https://doi.org/10.5194/acp-11-3212011, 2011.

Huang, L., McDonald-Buller, E. C., McGaughey, G., Kimura, Y., and Allen, D. T.: The impact of drought on ozone dry deposition over eastern Texas, Atmos. Environ., 127, 176-186, https://doi.org/10.1016/j.atmosenv.2015.12.022, 2016.

Kavassalis, S. C. and Murphy, J. G.: Understanding ozonemeteorology correlations: A role for dry deposition, Geophys. Res. Lett., 44, 2922-2931, 2017.

Lamarque, J.-F., Bond, T. C., Eyring, V., Granier, C., Heil, A., Klimont, Z., Lee, D., Liousse, C., Mieville, A., Owen, B., Schultz, M. G., Shindell, D., Smith, S. J., Stehfest, E., Van Aardenne, J., Cooper, O. R., Kainuma, M., Mahowald, N., McConnell, J. R., Naik, V., Riahi, K., and van Vuuren, D. P.: Historical (1850-2000) gridded anthropogenic and biomass burning emissions of reactive gases and aerosols: methodology and application, Atmos. Chem. Phys., 10, 7017-7039, https://doi.org/10.5194/acp-10-7017-2010, 2010.

Lamarque, J.-F., Shindell, D. T., Josse, B., Young, P. J., Cionni, I., Eyring, V., Bergmann, D., Cameron-Smith, P., Collins, W. J., Doherty, R., Dalsoren, S., Faluvegi, G., Folberth, G., Ghan, S. J., Horowitz, L. W., Lee, Y. H., MacKenzie, I. A., Nagashima, T., Naik, V., Plummer, D., Righi, M., Rumbold, S. T., Schulz, M., Skeie, R. B., Stevenson, D. S., Strode, S., Sudo, K., Szopa, S., 
Voulgarakis, A., and Zeng, G.: The Atmospheric Chemistry and Climate Model Intercomparison Project (ACCMIP): overview and description of models, simulations and climate diagnostics, Geosci. Model Dev., 6, 179-206, https://doi.org/10.5194/gmd-6179-2013, 2013.

Lelieveld, J., Evans, J. S., Fnais, M., Giannadaki, D., and Pozzer, A.: The contribution of outdoor air pollution sources to premature mortality on a global scale, Nature, 525, 367-371, 10.1038/nature 15371, 2015.

Lin, M., Horowitz, L. W., Payton, R., Fiore, A. M., and Tonnesen, G.: US surface ozone trends and extremes from 1980 to 2014 : quantifying the roles of rising Asian emissions, domestic controls, wildfires, and climate, Atmos. Chem. Phys., 17, 29432970, https://doi.org/10.5194/acp-17-2943-2017, 2017.

Malm, W. C., Sisler, J. F., Huffman, D., Eldred, R. A., and Cahill, T. A.: Spatial and seasonal trends in particle concentration and optical extinction in the United States, J. Geophys. Res.-Atmos., 99, 1347-1370, 1994.

Minnis, P., Sun-Mack, S., Young, D. F., Heck, P. W., Garber, D. P. , Chen, Y., Spangenberg, D. A., Arduini, R. F., Trepte, Q. Z., Smith, W. L., Ayers, J. K., Gibson, S. C., Miller, W. F., Hong, G., Chakrapani, V., Takano, Y., Liou, K. N., Xie, Y., and Yang, P.: CERES edition-2 cloud property retrievals using TRMM VIRS and Terra and Aqua MODIS data - Part I: Algorithms, IEEE T. Geosci. Remote, 49, 4374-4400, 2011.

Moss, R. H., Edmonds, J. A., Hibbard, K. A., Manning, M. R., Rose, S. K., Van Vuuren, D. P., Carter, T. R., Emori, S., Kainuma, M., and Kram, T.: The next generation of scenarios for climate change research and assessment, Nature, 463, 747-756, 2010.

Nielsen-Gammon, J. W.: The 2011 Texas drought, Texas Water Journal, 3, 59-95, 2012.

Pegoraro, E., Rey, A., Greenberg, J., Harley, P., Grace, J., Malhi, Y., and Guenther, A.: Effect of drought on isoprene emission rates from leaves of Quercus virginiana Mill, Atmos. Environ., 38, 6149-6156, 2004.

Prospero, J. M. and Lamb, P. J.: African droughts and dust transport to the Caribbean: Climate change implications, Science, 302, 1024-1027, 2003.

Qu, W., Wang, J., Zhang, X., Yang, Z., and Gao, S.: Effect of cold wave on winter visibility over eastern China, J. Geophys. Res.Atmos., 120, 2394-2406, 2015.

Randerson, J., Chen, Y., Werf, G., Rogers, B., and Morton, D.: Global burned area and biomass burning emissions from small fires, J. Geophys. Res.-Biogeo., 117, https://doi.org/10.1029/2012jg002128, 2012.

Rosenzweig, C., Iglesias, A., Yang, X., Epstein, P. R., and Chivian, E.: Climate change and extreme weather events; implications for food production, plant diseases, and pests, Global change \& human health, 2, 90-104, 2001.

Seco, R., Karl, T., Guenther, A., Hosman, K. P., Pallardy, S. G., Gu, L., Geron, C., Harley, P., and Kim, S.: Ecosystem-scale volatile organic compound fluxes during an extreme drought in a broadleaf temperate forest of the Missouri Ozarks (central USA), Glob. Change Biol., 21, 3657-3674, 2015.

Scanlon, B. R., Duncan, I., and Reedy, R. C.: Drought and the water-energy nexus in Texas, Environ. Res. Lett., 8, 045033, https://doi.org//10.1088/1748-9326/8/4/045033, 2013.
Schnell, J. L. and Prather, M. J.: Co-occurrence of extremes in surface ozone, particulate matter, and temperature over eastern North America, P. Natl. Acad. Sci. USA, 114, 2854-2859, 2016.

Schnell, J. L., Prather M. J., Josse, B., Naik, V., Horowitz, L.W., Zeng, G., Shindell, D. T., and Faluvegi, G.: Effect of climate change on surface ozone over North America, Europe, and East Asia. Geophys. Res. Lett., 43, 3509-3518, 2016.

Shen, L., Mickley, L. J., and Murray, L. T.: Influence of 2000-2050 climate change on particulate matter in the United States: results from a new statistical model, Atmos. Chem. Phys., 17, 43554367, https://doi.org/10.5194/acp-17-4355-2017, 2017.

Steiner, A. L., Davis, A. J., Sillman, S., Owen, R. C., Michalak, A. M., and Fiore, A. M.: Observed suppression of ozone formation at extremely high temperatures due to chemical and biophysical feedbacks, P. Natl. Acad. Sci. USA, 107, 19685-19690, 2010.

Stephens, G. L., Wood, N. B., and Gabriel, P. M.: An assessment of the parameterization of subgrid-scale cloud effects on radiative transfer. Part I: Vertical overlap, J. Atmos. Sci., 61, 715-732, 2004.

Tai, A. P. K., Mickley, L. J., and Jacob, D. J.: Correlations between fine particulate matter $\left(\mathrm{PM}_{2.5}\right)$ and meteorological variables in the United States: Implications for the sensitivity of $\mathrm{PM}_{2.5}$ to climate change, Atmos. Environ., 44, 3976-3984, https://doi.org/10.1016/j.atmosenv.2010.06.060, 2010.

Taylor, K. E., Stouffer, R. J., and Meehl, G. A.: An overview of CMIP5 and the experiment design, B. Am. Meteorol. Soc., 93, https://doi.org/10.1175/BAMS-D-11-00094.1, 2012.

Tian, H., Ren, W., Tao, B., Sun, G., Chappelka, A., Wang, X., Pan, S., Yang, J., Liu, J., and Felzer, B.: Climate extremes and ozone pollution: a growing threat to China's food security, Ecosystem Health and Sustainability, 2, https://doi.org/10.1002/ehs2.1203, 2016.

Tosca, M. G., Randerson, J. T., Zender, C. S., Flanner, M. G., and Rasch, P. J.: Do biomass burning aerosols intensify drought in equatorial Asia during El Niño?, Atmos. Chem. Phys., 10, 35153528, https://doi.org/10.5194/acp-10-3515-2010, 2010.

Trenberth, K. E., Dai, A., van der Schrier, G., Jones, P. D., Barichivich, J., Briffa, K. R., and Sheffield, J.: Global warming and changes in drought, Nature Climate Change, 4, 17-22, 2014.

University of East Anglia Climatic Research Unit, Harris, I. C. and Jones, P. D.: CRU TS3.22: Climatic Research Unit (CRU) Time-Series (TS) Version 3.22 of High Resolution Gridded Data of Month-by-month Variation in Climate (January 1901December 2013), NCAS British Atmospheric Data Centre, 24 September 2014, https://doi.org/10.5285/18BE23F8-D252482D-8AF9-5D6A2D40990C, 2014.

U.S. Environmental Protection Agency (EPA): Technology Transfer Network Clearinghouse for Inventories and Emission Factors, National Emissions Inventory (NEI) air pollutant emissions trendsdata, available at: https://www.epa.gov/ air-emissions-inventories/air-pollutant-emissions-trends-data (last access: 10 February 2017), 2016.

van der Werf, G. R., Randerson, J. T., Giglio, L., Collatz, G. J., Mu, M., Kasibhatla, P. S., Morton, D. C., DeFries, R. S., Jin, Y., and van Leeuwen, T. T.: Global fire emissions and the contribution of deforestation, savanna, forest, agricultural, and peat fires (1997-2009), Atmos. Chem. Phys., 10, 11707-11735, https://doi.org/10.5194/acp-10-11707-2010, 2010. 
Vicente-Serrano, S. M., Beguería, S., and López-Moreno, J. I.: A Multiscalar Drought Index Sensitive to Global Warming: The Standardized Precipitation Evapotranspiration Index, J. Climate, 23, 1696-1718, https://doi.org/10.1175/2009jcli2909.1, 2010.

Wang, J. X. L. and Angell, J. K.: Air Stagnation Climatology for the United States. NOAA/Air Resource Laboratory. ATLAS No. $1,1999$.

Wang, Y., Xie, Y., Cai, L., Dong, W., Zhang, Q., and Zhang, L.: Impact of the 2011 southern us drought on ground-level Fine aerosol concentration in summertime, J. Atmos. Sci., 72, 10751093, 2015.

Westerling, A. L. and Swetnam, T. W.: Interannual to decadal drought and wildfire in the western United States, EOS, Transactions American Geophysical Union, 84, 545-555, 2003.

Westerling, A. L., Gershunov, A., Brown, T. J., Cayan, D. R., and Dettinger, M. D.: Climate and wildfire in the western United States, B. Am. Meteorol. Soc., 84, 595-604, 2003.
Xu, L., Guo, H., Boyd, C. M., Klein, M., Bougiatioti, A., Cerully, K. M., Hite, J. R., Isaacman-VanWertz, G., Kreisberg, N. M., and Knote, C.: Effects of anthropogenic emissions on aerosol formation from isoprene and monoterpenes in the southeastern United States, P. Natl. Acad. Sci. USA, 112, 37-42, 2015.

Zhang, H., Wang, Y., Park, T.-W., and Deng, Y.: Quantifying the relationship between extreme air pollution events and extreme weather events, Atmos. Res., 188, 64-79, https://doi.org/10.1016/j.atmosres.2016.11.010, 2017.

Zhang, Y. and Wang, Y.: Climate driven ground-level ozone extreme in the fall over the Southeast United States, P. Natl. Acad. Sci. USA, 113, 10025-10030, https://doi.org/10.1073/pnas.1602563113, 2011. 